8-2016

\title{
Medium Altitude Long Endurance Remotely Piloted Aircraft Training: a Pilot Study in Blended Learning
}

Zachary P. Waller

University of North Dakota, zachary.waller@und.edu

Thomas Petros

University of North Dakota, thomas.petros@und.edu

John Bridewell

Scott Kroeber

University of North Dakota, scott.kroeber@und.edu

Neil Nowatzki

University of North Dakota, neil.nowatzki@und.edu

How does access to this work benefit you? Let us know!

Follow this and additional works at: https://commons.und.edu/avi-fac

Part of the Aviation Commons

\section{Recommended Citation}

Zachary P. Waller, Thomas Petros, John Bridewell, et al.. "Medium Altitude Long Endurance Remotely Piloted Aircraft Training: a Pilot Study in Blended Learning" (2016). Aviation Faculty Publications. 2. https://commons.und.edu/avi-fac/2

This Article is brought to you for free and open access by the Department of Aviation at UND Scholarly Commons. It has been accepted for inclusion in Aviation Faculty Publications by an authorized administrator of UND Scholarly Commons. For more information, please contact und.commons@library.und.edu. 


\title{
PEER-REVIEWED ARTICLE \\ MEDIUM ALTITUDE LONG ENDURANCE REMOTELY PILOTED AIRCRAFT TRAINING: A PILOT STUDY IN BLENDED LEARNING
}

\author{
Zachary P. Waller \\ Aviation Researcher and Lecturer, University of North Dakota \\ Thomas V. Petros \\ Professor of Psychology, University of North Dakota \\ Dr John Bridewell \\ Professor of Aviation, University of North Dakota \\ Scott Kroeber \\ Faculty Research Assistant, University of North Dakota \\ Neil Nowatzki \\ Multimedia Specialist, University of North Dakota
}

\begin{abstract}
Since April of 2011, research and development efforts between the Air Force Research Laboratory (AFRL) and the University of North Dakota (UND) have progressed through the "Science and Technology for Warfighter Training and Aiding." Cooperative Agreement. One product of these cooperative efforts has been a Heads Down Display (HDD) Menu Trainer. Designed to familiarize students with the layout and manipulation of the HDD menus for either the MQ-1 or MQ-9, a parallel pretest/posttest design was designed to examine the efficacy of this HDD menu trainer as training aid in traditional, blended, and distance pedagogies.

Results of a mixed ANOVA indicated the trainer significantly improved performance from pretest to posttest scores across all groups $(p<0.001)$, however comparing these scores according to instructional intervention (i.e. Traditional, Blended, and Distance) found no significant effect. No significant differences were observed between pretest, posttest, or percent change scores according to instructional intervention. Analysis of the same variables with respect to pilot certification revealed that learners holding a Commercial pilot certificate scored significantly higher on the pretest than those with no FAA (Federal Aviation Administration) pilot certification $(p<0.05)$, and learners with no FAA pilot certificate demonstrated significantly higher percent changes from pretest to posttest than learners with Commercial pilot certificates $(p<0.05)$. While, it is clear that the HDD menu trainer has demonstrated effectiveness in improving a student's ability to navigate and manipulate the MQ-9 menu structure, the subtle differences between instructional methods will require further investigation. Future studies are encouraged to investigate the benefits and effectiveness of each instructional method while controlling for pilot certification.
\end{abstract}


In the past two decades, the availability and capability of computer technologies have greatly expanded the educational options available to learners and instructors alike (Osguthorpe \& Graham, 2003). Integrating these advances into pedagogy, which recognizes and capitalizes on the inherent strengths of both traditional (i.e. face-to-face) and distance systems of delivery, is the challenge that blended learning offers. Computer Based Training (CBT) modules offer a specific and contemporary example of these expanded educational options, and have been defined as "... self-contained, interactive, often asynchronous, computer-based program[s] designed for self-paced instruction that uses features of learner control coupled with predesigned material, required responses and feedback" (Bedwell \& Salas, 2010, p. 240).

\section{Statement of the Problem}

Since April of 2011, research and development efforts between the Air Force Research Laboratory (AFRL) and the University of North Dakota (UND) have progressed through the "Science and Technology for Warfighter Training and Aiding." Cooperative Agreement. This CA (FA8650-11-2-6212), is producing a state-of-the-art curriculum for Medium Altitude, Long Endurance Remotely Piloted Aircraft (MALE RPA) pilots and sensor operators, as well as establishing infrastructure for future research efforts. One product of these cooperative efforts has been a Heads Down Display (HDD) Menu Trainer. This CBT module, developed by UND's Aerospace Network, was designed to familiarize students with the layout and manipulation of the HDD menus for either the MQ-1 or MQ-9.

The efficacy of the HDD menu trainer to improve a student's ability in navigating and manipulating the MQ-9 menu structure, as well as its application as training aid in blended pedagogy, or standalone teaching tool in distance pedagogy have not yet been examined. This need for evaluative validation fits well into gaps in extant literature regarding Computer Aided Instruction (CAI) (Adler \& Johnson, 2000). In characterizing literature related to CAI, Adler and Johnson (2000) concluded that evaluation articles on the topic remain uncommon in comparison to demonstrations and media-comparative studies, and call for future research to be more aware of these gaps if CAI literature is to mature.

\section{Purpose of the Study}

The purpose of this pilot study was to examine the expertise of students in navigating and manipulating the HeadsDown Display (HDD) menus of MALE RPA when provided either traditional, blended, or distance instruction. Learner knowledge gains between groups were measured by both pretest and posttest assessments to assess the effectiveness (1) of the HDD menu trainer, and (2) its potential for use in a variety of instructional methods.

\section{Literature Review}

\section{Blended learning}

While used frequently throughout academic journals and conferences (Osguthorpe \& Graham, 2003), a strict definition of blended learning appears elusive in the extant literature. In his work describing the definitions and directions of blended learning environments, Osguthorpe (2003) offered that,

"Blended learning combines face-to-face with distance delivery systems... the internet is involved, but it's more than showing a page from a website on the classroom screen. And it all comes back to teaching methodologies - pedagogies that change according to the unique needs of learners. Those who use blended learning environments are trying to maximize the benefits of both faceto-face and online methods - using the web for what it does best, and using class time for what it does best." (Osguthorpe \& Graham, 2003, p. 227)

Osguthorpe and Graham (2003) stress that blended approaches are based upon the assumption that inherent benefits, and weaknesses, exist for both face-to-face interaction and distance delivery. Educators employing blended approaches to instruction must discern the best balance between online access to knowledge and face-to-face human interaction as they develop each course (Osguthorpe \& Graham, 2003). Evaluative works on curricula which fall under Osguthorpe and Graham's (2003) working definition of blended learning strategies, or are specific to Bedwell \& Salas (2010) definition of CBT, are reviewed in the sections that follow. These efforts have been organized 
according to domains regarding (1) knowledge gains, (2) learner attitudes, and (3) learning efficiency, as offered by Chumley-Jones, Dobbie, and Alford (2002).

\section{Learner knowledge gains}

Efforts addressing learner knowledge gains have assessed change in participant performance as a result of intervention with some manner of computer assisted, or computer based instruction. The majority of studies in this domain measured change using multiple choice test-scores. Pretest/posttest self-controlled studies were the most common design, however others such as self-selected controlled studies, assigned crossover trials, and randomized controlled trials methodologies were also noted (Chumley-Jones et al. 2002). Several within-group methodologies were able to successfully document significant increases in performance as a result of distance instruction (Boyle, Bradley, Chalk, Jones, \& Pickard, 2003; Curran, Hoekman, Gulliver, Landells, \& Hatcher, 2000; Engel, Crandall, Basch, Zybert, \& Wylie-Rosett, 1997; Francis, Mauriello, Phillips, Englebardt, \& Grayden, 2000; Harris, Salasche, \& Harris, 2001; Kronz, Silberman, Allsbrook Jr., \& Epstein, 2000; Perryer, Walmsley, Barclay, Shaw, \& Smith, 2002).

Although within-group assessments of distance instruction were common, between group methodologies allow comparisons to be made across or against alternative pedagogical strategies (i.e. traditional face-to-face, blended, and standalone distance). In these designs, literature which indicated a lack of significant difference in terms of knowledge gains appear to be the majority when distance and traditional pedagogies are compared (Baumlin, Bessette, Lewis, \& Richardson, 2000; Bell, Fonarow, Hays, \& Mangione, 2000; Block, Felix, Udermann, Reineke, \& Murray, 2008; Rivera \& Rice, 2002; Rose, Frisby, Hamlin, \& Jones, 2000; Sakowski, Rich, \& Turner, 2001; Woo \& Kimmick, 2000). Allen, Mabry, Mattrey, Bourhis, Titsworth, \& Burrell (2004) also found little distinction between traditional and distance learning classrooms on the basis of performance, but offer that no clear decline in educational effectiveness is noted when utilizing distance education technology.

Other between-groups designs did identify significant differences in favor of distance and blended pedagogies. For example, in their examination of potential pedagogic advantages of distance methods of instruction, Lipman, Sade, Glotzbach, Lancaster, and Marshall (2001) compared a traditional classroom course with the same course supplemented by internet-based discussion. Results indicated that performance was higher $(p<0.005)$ in the blended course than the traditional course (Lipman et al. 2001). Melton, Graf, and Chopak-Foss (2009) compared student achievement in blended and traditional pedagogies with mixed results. However, the grades of students in the blended course were found to be significantly higher $(p<0.05)$ than those in the traditional course (Melton et al. 2009).

In 2007, Pereira, Pleguezuelos, Meri, Molina-Ros, Molina-Tomas, and Masdeu, examined the efficiency of blended pedagogy, and found that students receiving blended learning received significantly higher grades $(p<0.0001)$ than those in the traditional group (Pereira, et al., 2007). Student feedback also indicated that students felt the course design was an effective (88\%) and efficient (92\%) method of learning, and helped to familiarize them with resources on the internet (96\%) (Pereira, et al., 2007). Further, students' confidence, measured before and after the intervention, showed significant improvement $(\mathrm{p}<0.001)$.

\section{Learner attitudes}

Since, the late 1990's students have valued the “...flexibility, timeliness, efficiency and breadth of access to relevant information offered by the [internet]" (Agius \& Bagnall, 1998, p. 337). Another facet commonly used to evaluate pedagogy, and the second category offered by Chumley-Jones et al. (2002), learner attitudes have been measured and examined regularly in the extant literature.

In their study, Baumlin, et al. (2000) examined course satisfaction with a participant survey. Results indicated that $65 \%$ of participants said they wanted computer-assisted instruction as an adjunct to their course curricula, but only $28 \%$ of the students with access actually utilized the module. Participants who did use it rated it useful (4.2/5), easy to use (4.4/5), and easy to access (4.1/5). Of the students with access to the online module who chose not to use it, $77.8 \%$ reported a lack of time as the reason for not using the module (Baumlin, et al. 2000). In Bell et al. (2000), ratings on a learner satisfaction scale indicated that students using the online tutorial displayed higher satisfaction with the curriculum (Bell et al. 2000). 


\section{JOUNNAL|UNMANNED \\ of AERIAL SYSTEMS}

The 2000 work of Curran et al. also made a general measure of learner attitude. Participants indicated high satisfaction with the self-paced instruction and use of the asynchronous computer conferencing for collaboration among colleagues (Curran et al. 2000). A voluntary satisfaction survey by Harris et al. (2001), indicated extremely high user satisfaction with a distance curriculum. A learner satisfaction survey by Melton et al. (2009), indicated higher satisfaction from students receiving blended learning course delivery $(p<0.01)$. Authors concluded that the blended course delivery was preferred over the traditional lecture format, challenging teachers' traditional approach to delivering general health courses at the university level (Melton et al. 2009). Horsch, Balback, Melnitzki, and Knauth (2000) conducted a simple survey design to measure learner attitudes regarding a distance course. On a scale of 1 to $5,(1=$ very good; $5=$ very bad $)$ students $(\mathrm{n}=32)$ rated the online module at 1.93 . In a self-assessment of knowledge gained, 18 of 32 students indicated they had acquired new knowledge, and 10 indicated that learning with the online text was more efficient than learning with a conventional textbook (Horsch et al. 2000).

Hsu and Hsieh (2011) utilized four scales (i.e. the Case Analysis Attitude Scale, Case Analysis Self-Evaluation Scale, Blended Learning Satisfaction Scale, and Metacognition Scale) for students to rate their own performance in blended and traditional delivery courses. Results indicated no difference between groups on any of the self-reported performance scales measured at pretest and posttest. Authors offer that these results demonstrate that both blended learning and traditional classroom lectures are both effective avenues for presenting materials and exchanging ideas to understand course content, and recommend that newly developed course modules and innovative course components should be tested repeatedly for effectiveness (Hsu \& Hsieh, 2011). Smyth, Houghton, Cooney, and Casey (2012) interviewed focus groups of students regarding their blended learning experience, and found that students received the blended learning method positively, but offered that the online component meant little time away from study, suggesting that it was more invasive on their everyday life (Smyth et al. 2012).

In their examination of the effectiveness of traditionally and distance courses, Rose et al. (2005) also made a point to measure student satisfaction. No significant differences were reported for (1) communication with classmates, (2) instructor, (3) assignments, (4) review sessions, (5) relevance of course, or (6) the overall course (Rose et al. 2000). Pereira et al. (2007) also observed no statistical difference in overall satisfaction between their blended and traditional courses. Rivera and Rice (2002), who conducted a pilot study evaluating three class formats (i.e. traditional, distance, and blended) found that measures of student satisfaction seemed to indicate that relative to the traditional and blended courses, students in the distance course were less satisfied. Woo and Kimmick (2000) also compared student satisfaction, but found that participants in the distance course reported significantly higher $(p<0.05)$ stimulation of learning compared to those in the traditional lecture course.

As with the efforts addressing learner knowledge gains, measurements of learner attitudes have returned mixed responses. Aside from noting a positive disposition toward pedagogies utilizing some manner of computer assisted, or computer based instruction from the majority of the works, these results are difficult to generalize. While measuring learner attitudes toward experimental curriculums appears commonplace, there seems to be little standardization or congruence in method of measurement.

\section{Learning efficiency}

The final and briefest of the three categories examined is learning efficiency. Requiring at minimum a between groups comparison for quantitative results, measures of learning efficiency for interventions with some manner of computer assisted, or computer based instruction compared to traditional delivery methods are rare. Only two studies were identified as addressing this topic. The first was also reviewed in the learner attitude section. In their examination of knowledge gains, learning efficiency and learner satisfaction between an online tutorial program and printed materials, Bell et al. (2000) assessed students $(n=162)$ enrolled in family medicine and internal medicine residency programs at four universities. Results indicated no significant difference in posttest scores between those students using the online tutorial and the printed text materials. However, those utilizing the online tutorial spent less time studying $(p<0.001)$, demonstrating greater learning efficiency. The second study, also reviewed in the learner attitudes section was a simple survey study design to collect student attitudes regarding a distance medical course. In a self-assessment of knowledge gained, 18 of 32 students indicated they had acquired new knowledge, and 10 indicated that learning with the online text was more efficient than learning with a conventional textbook (Horsch et al. 2000). As with program cost, a fourth category offered by Chumley-Jones et al. (2002), this category of evaluative research regarding computer assisted, or computer based instruction requires further exploration. 


\section{METHODOLOGY}

The present study examined the effectiveness of the HDD menu trainer in improving a student's ability to navigate and manipulate the MQ-9 menu structure, as well as potential impacts of either traditional, blended, or distance instruction on this process. Using the HDD menu trainer developed under the "Science and Technology for Warfighter Training and Aiding." Cooperative Agreement between AFRL and UND, pretests and posttests were used to measure learner knowledge gain. Learner attitude was assessed using a satisfaction survey.

\section{Sample}

The sample for this study consisted of individuals both with and without FAA pilot certification at the University of North Dakota John D. Odegard School of Aerospace Sciences $(n=15)$. Of this sample, 3 participants held no FAA pilot certificate, 5 participants held a Private Pilot Certificate, and 7 participants carried Commercial Pilot certification. The average subject age was 27.73. Subject responses were not separated by race or gender, and no subject's results were excluded from analysis. Participants were randomly assigned to one of three groups (i.e. Traditional, Distance, and Blended) receiving various instructional interventions with respect to MQ-9 HDD menus.

\section{Instrument}

The HDD menu trainer, developed by UND's Aerospace Network was designed to familiarize students with the layout and manipulation of the HDD menus for either the MQ-1 or MQ-9. The trainer contains (1) a tutorial describing menu layout, menu navigation, button types, and button arrangement, (2) a walk-through function, which guides students through each root menu and its submenus, (3) an exercise function, which tests the student's ability to navigate and execute specific commands within a set time limit, and finally (4) a freeplay function, which allows the students to navigate and explore the HDD menus without specific focus or limits on time.

The menu trainer was delivered to the distance and blended groups via an open source, online Learning Management System (LMS) administered by the researcher. All subjects had access to the LMS for completion of the pretest and posttest measures. Subjects were briefed on use of the LMS at the start of the intervention.

The pretest and posttest measures utilized a modified version of the HDD menu trainer's exercise function. These assessments, designed by an Original Equipment Manufacturer (OEM) certified MQ-9 IP, reflect those menu functions most commonly used or most critical for gauging a student's expertise with navigating and manipulating the HDD menus. Roughly 25 pilot orientated menu functions were selected from the pool of 260 which constitute the menu trainer's exercise function, and were adapted for delivery as the pretest and posttest measures. These measures, like the menu trainer's exercise function, measure the student's ability to navigate and execute specific commands within a set time limit. Performance was assessed according both the speed and accuracy of the student's response.

\section{Data Collection and Analysis}

This study was reviewed and approved by the University of North Dakota's Institutional Review Board. Subjects were informed of the study with advertisements posted throughout the campus aerospace facilities as well as the aviation student email listserve. Subjects were briefed on the purpose and nature of the study prior to participation. Due to the sensitive nature of the MQ-9 HDD menus, participants were also required to present proof of U.S. citizenship by means of a passport, and/or birth certificate and driver's license and sign an International Traffic in Arms Regulations (ITAR) Statement of Understanding.

Subjects were randomly assigned to one of three study groups to receive instruction on navigating and manipulating the HDD menus of the MQ-9. As illustrated in Table 1, students assigned to the distance group were granted access to the HDD menu trainer. Subjects assigned to the blended group were granted access to the HDD menu trainer, but also attended a classroom discussion guided by an Original Equipment Manufacturer (OEM) certified MQ-9 Instructor Pilot (IP). Subjects assigned to the traditional group were not granted access to the HDD menu trainer, but received a lecture and lesson on the HDD Menus from an OEM certified MQ-9 IP. The lesson completed by the traditional group was conducted using an MQ-9 part-task trainer which simulated the same HDD menus but provided no innate instructional aspects (i.e. no tutorial, walk-through, or exercise functions). The layout and functionality of the menus simulated in this part-task trainer were identical to those used in the pretest and posttest measures, as well as those used by the distance and blended groups. 


\begin{tabular}{lccc}
\hline & Traditional & Blended & Distance \\
& Group & Group & Group \\
\hline HDD Menu Trainer & No & Yes & Yes \\
MQ-9 Instructor Pilot & Yes & Yes & No \\
\hline
\end{tabular}

Table 1, Research Design

Descriptive and inferential statistics were collected from the data. The means, standard deviations, minimum, maximum, range, and measures of skewness and kurtosis indices were calculated using raw scores from each group. A one way ANOVA was used to assess differences between the groups on pretest, posttest, and percent change scores. In cases where parametric assumptions were violated, Kruskal-Wallis non-parametric procedures were used to assess potential relationships. Significance in all statistical tests were set at a minimum of $p<0.05$.

\section{RESULTS}

\section{Learner Knowledge Gains}

Illustrated in Table 2 are descriptive statistics for each of the three groups in their pretest, posttest, and percent change measures. Each task in the parallel pretest and posttest measures was assigned 15 possible points. Points were deducted for incorrect keystrokes as well as when a task could not be completed inside 30 seconds. If a task was skipped, a score of 0 was assigned. Percent change was calculated as the difference between the pretest and posttest score divided by the pretest Score. Also included in Table 2 are z-scores for the skewness and kurtosis of each factor's score distribution. For these measures, absolute values greater than 1.96 indicate significantly non-normal distributions at $p<0.05$ (Field, 2009). Except for skewness in the percent change measure of the distance group, all measure distributions failed to differ significantly from a normal distribution in either skewness or kurtosis.

\begin{tabular}{lccccccc}
\hline & N & Mean & SD & Minimum & Maximum & $\begin{array}{c}\text { Z } \\
\text { skewness }\end{array}$ & Z kurtosis \\
\hline $\begin{array}{l}\text { PRE-TEST } \\
\quad \text { Traditional }\end{array}$ & 5 & 244.00 & 68.58 & 157.00 & 324.00 & 0.00 & -0.86 \\
$\quad$ Blended & 5 & 264.60 & 49.26 & 191.00 & 309.00 & -0.87 & -0.23 \\
$\quad$ Distance & 5 & 270.40 & 56.79 & 175.00 & 326.00 & -1.70 & 1.57 \\
POST-TEST & & & & & & & \\
Traditional & 5 & 331.40 & 26.95 & 308.00 & 365.00 & 0.67 & -1.45 \\
Blended & 5 & 334.00 & 27.59 & 299.00 & 371.00 & 0.21 & -0.26 \\
$\quad$ Distance & 5 & 332.00 & 25.95 & 308.00 & 366.00 & 0.48 & -0.58 \\
PERCENT CHANGE & & & & & & & \\
Traditional & 5 & 42.91 & 33.28 & 12.65 & 96.18 & 1.34 & 0.73 \\
Blended & 5 & 28.85 & 18.41 & 6.47 & 56.54 & 0.72 & 0.58 \\
Distance & 5 & 27.26 & 28.14 & 5.12 & 76.00 & $2.07 *$ & 1.92 \\
\hline
\end{tabular}

* Indicates significance at the 0.05 level 
Results of the one way ANOVA (Table 3) comparing pretest, posttest, and percent change scores between groups found no significant differences between the three groups on any of the measures. Although non-normality was noted in the skewness of the distance group in percent change, the same patterns of significance were noted using nonparametric Kruskal-Wallis procedures comparing the mean ranks of percent change, as well as pretest and posttest scores, with respect to instructional method.

\begin{tabular}{|c|c|c|c|c|c|c|c|}
\hline & \multicolumn{2}{|c|}{$\begin{array}{c}\text { Traditional } \\
\text { Group }\end{array}$} & \multicolumn{2}{|c|}{$\begin{array}{l}\text { Blended } \\
\text { Group }\end{array}$} & \multicolumn{2}{|c|}{$\begin{array}{c}\text { Distance } \\
\text { Group }\end{array}$} & \multirow[b]{2}{*}{$\mathrm{P}$} \\
\hline & Mean & $\mathrm{SD}$ & Mean & SD & Mean & SD & \\
\hline PRE-TEST & 244.00 & 68.58 & 264.60 & 49.26 & 270.40 & 56.79 & 0.761 \\
\hline POST-TEST & 331.40 & 26.95 & 334.00 & 27.59 & 332.00 & 25.95 & 0.987 \\
\hline PERCENT CHANGE & 42.91 & 33.28 & 28.85 & 18.41 & 27.26 & 28.14 & 0.620 \\
\hline
\end{tabular}

Table 3, One Way ANOVA Results According to Instructional Method

A mixed ANOVA indicated the trainer significantly improved performance from pretest to posttest scores across all groups $F(1,12)=49.01 \quad(p<0.001)$, however comparing these scores by instructional intervention (i.e. Traditional, Blended, and Distance) found no significant effect. To summarize, an overall effect of instruction was observed, but did not vary across the three types of instructional intervention.

\section{Regarding pilot certification}

Analysis of pretest and posttest scores, as well as percent change in scores with respect to pilot certification revealed several relationships meriting consideration for future studies in this area. In Table 4, results of a one way ANOVA and Tukey post hoc analysis indicated that participants holding a commercial pilot certificate scored significantly higher on the pretest than those with no FAA pilot certification $(p<0.05)$. No significant effect of pilot certification was found in an analysis of the post test scores. Furthermore, significantly higher percent changes from pretest to posttest were observed in participants with no FAA pilot certificate than those with commercial certificates $(p<0.05)$. Again, a similar pattern of results were found when analysis was repeated using the Kruskal-Wallis procedure.

\begin{tabular}{|c|c|c|c|c|c|c|c|}
\hline & \multicolumn{2}{|c|}{$\begin{array}{l}\text { None } \\
(\mathrm{n}=3)\end{array}$} & \multicolumn{2}{|c|}{$\begin{array}{l}\text { Private } \\
(\mathrm{n}=5)\end{array}$} & \multicolumn{2}{|c|}{$\begin{array}{l}\text { Commercial } \\
\quad(\mathrm{n}=7)\end{array}$} & \multirow[b]{2}{*}{$\mathrm{P}$} \\
\hline & Mean & SD & Mean & SD & Mean & SD & \\
\hline PRE-TEST & 191.67 & 17.00 & 258.80 & 67.11 & 289.43 & 27.92 & $0.024 *$ \\
\hline POST-TEST & 306.00 & 6.25 & 339.20 & 25.15 & 339.00 & 23.90 & 0.114 \\
\hline PERCENT CHANGE & 60.45 & 14.01 & 37.88 & 34.05 & 17.77 & 10.47 & $0.041 *$ \\
\hline
\end{tabular}

* Indicates significance at the 0.05 level

Table 4, One Way ANOVA results According to Pilot Certification 


\section{Learner Attitudes}

A learner satisfaction survey was used to gauge participant satisfaction with the instruction they received. Participants were asked to respond to 8 statements regarding course satisfaction on a five point Likert scale (1=Strongly Disagree; 5=Strongly Agree). Sum totals and descriptive statistics for these responses are found in Table 5 below. While results of a one way ANOVA did not indicate a significant difference between course satisfaction and instructional method, patterns in the open ended responses offer some differentiation.

\begin{tabular}{lccccccc}
\hline & N & Mean & SD & Minimum & Maximum & $\begin{array}{c}\text { Z } \\
\text { skewness }\end{array}$ & Z kurtosis \\
\hline ATTITUDE & & & & & & & \\
$\quad$ Traditional & 5 & 29.20 & 5.45 & 22 & 35 & -0.59 & -0.99 \\
Blended & 5 & 32.60 & 6.23 & 23 & 39 & -1.02 & -0.38 \\
$\quad$ Distance & 5 & 29.00 & 1.00 & 28 & 30 & 0.00 & -1.50 \\
\hline * Indicates significance at the 0.05 level & & & & & & \\
\hline
\end{tabular}

Table 5, Descriptive Results of Learner Attitude

Open-ended responses to the prompts "Please describe improvements, if any, which would better assist your learning of the course material." and "Please describe specific aspects of the course or instruction which promoted your learning." provide qualitative context. Members of the traditional group commonly felt that additional time and access to the HDD trainer would have better assisted their learning "... As someone who prefers to study alone, access to the trainer", "More time to teach the material", "More time with software" and "I would have benefitted from some practice exams at home." While the ability to govern instructional pace was a common theme in aspects of the course which promoted learning for members of the distance group, preference for an introductory lecture preceding self-study was noted as a way to better assist their learning. In the blended group, the combination of selfpaced practice and the availability of instructor expertise in classroom discussions surfaced as positive aspects of the course.

\section{Learning Efficiency}

The traditional group was presented a 15 minute lecture followed by a simulated lesson in a part-task trainer Ground Control Station (GCS) for 45 minutes. As a single crew includes 1 pilot position and 1 sensor operator, this instruction only permitted 2 individuals to work directly with the IP at a time, while the remainder of the class observed. Following this lesson, participants were not allowed access to the menus excluding a 1 hour practice period in the simulated GCS. Self-reported study times for the distance group indicated an average of 1.3 hours of effort ( 0.84 $S D$ ) with the HDD menu trainer. Finally the self-reported study times for the blended group showed an average of 3.5 hours of effort $(2.58 S D)$ preceding a 1 hour classroom discussion and review prior to the posttest.

\section{DISCUSSION}

The results above demonstrate that the HDD menu trainer is effective in improving a student's ability to navigate and manipulate the MQ-9 menu structure. Results for learner knowledge gains, learner attitudes, and learning efficiency offer preliminary indications of the trainer's potential as training aid in blended pedagogy, as well as standalone teaching tool in distance pedagogy. Similar to many previous efforts reviewed, the HDD menu trainer was at least as effective as the traditional method of instruction currently used in terms of learner knowledge gains. Although inferential results of the learner satisfaction survey did not reflect differing levels of satisfaction, written responses to the open ended portions of the instrument indicated that learners clearly identified with classic strengths 
and weaknesses of both traditional and distance pedagogies. The group receiving traditional instruction benefitted from the interaction and expertise of the live instructor, but requested additional time with the material or ways to study according to their individual needs. Members of the distance group, meanwhile, appreciated the ability to self-govern the pace of their learning but noted instructor availability as a way to improve their learning.

While it may have been anticipated that the blended group would outperform the other groups, benefitting from the advantages of instructor availability as well as the ability to govern their own preferences for pace and duration of instruction, the relatively small sample sizes likely affected this in two ways. First, if instructional method commands only a small effect size on learner knowledge gains, much larger sample sizes will be required to reliably detect a genuine effect when one exists. Second, as overall class size approaches the size of a single RPA crew, the unique differences between the instructor delivered portions of the blended and traditional approaches lessen. As class size approaches the size of a single crew, the lecture received by the traditional group increasingly resembles the individual attention normally reserved for individual lessons. Likewise, with fewer members of the blended group, individual members may benefit less from the questions and discussion generated between their peers and the instructor. As such, it may be that the blended pedagogy has a greater effect on learning knowledge gain and learning efficiency (in terms of instructor time) as class size increases.

\section{Conclusion and Future Studies}

As the availability and capability of instructional technologies continues to expand, opportunities to adapt, validate, and improve pedagogy accordingly are many. Extant literature reflecting evaluative efforts on distance and blended instruction generally report that these instructional methodologies are able to perform at least as well as traditional methods and in some circumstances, better. Blending the advantages of traditional face-to-face instruction with the benefits of computer aided delivery systems for learners is the focus of blended learning. The purpose of this pilot study has been to examine the expertise of students in navigating and manipulating the HDD menus of MALE RPA to assess (1) the effectiveness of the HDD menu trainer, and (2) its potential for use in traditional, blended, or distance instructional methods.

Results of a mixed ANOVA indicated the trainer significantly improved performance from pretest to posttest scores across all groups $(p<0.001)$, but comparisons by instructional intervention (i.e. Traditional, Blended, and Distance) found no significant effect. A lack of significant differences between pretest, posttest, and percent change scores between groups indicates that the HDD menu trainer may be assumed as equally effective in terms of learner knowledge gains across the instructional designs examined.

Exploration of the relationship between pilot certification and performance revealed an additional aspect influencing MALE RPA training, which must be controlled in future studies seeking variation uniquely attributable to instructional method. This pilot study found that learners holding a commercial pilot certificate scored significantly higher on the pretest than those with no FAA pilot certification $(p<0.05)$. Such tendencies beg further investigations into the relationship of FAA pilot certification and MALE RPA training. What skills, knowledge, or experience, captured by these aviation benchmarks, accounts for the increased initial performance? Is the lack of significant difference between posttest scores with respect to certification the result of an artificial ceiling effect with the instrument? Does the ability to navigate and manipulate these menus represent understanding of their function? Perhaps considerations such as these can be used to adapt initial operations training in these platforms to the qualifications of those best qualified or most likely to be entering this new and rapidly evolving discipline.

As demand for MALE RPA pilots and sensor operators grows, adapting pedagogy and technologies to provide the highest standard of instruction at the greatest efficiency will remain an enormous challenge for all. Future studies involving the HDD menu trainer are underway utilizing the results of this pilot effort to isolate the unique variance in performance explained by instructional method and possible interactions between instruction and pilot certification. Informed by the results of this study, these efforts will utilize larger samples to map this relationship. Other studies are encouraged to document and reflect on learning efficiency, investigating whether use of such training aids can reduce instructor and/or simulator training time while engendering equivalent knowledge, skills, and abilities. Examining the pedagogy of MALE RPA training with consideration to learner knowledge gains, learner attitude, and learning efficiency will support the comprehensive understanding necessary to advance and mature this training domain. 


\section{REFERENCES}

Adler, M., \& Johnson, K. (2000). Quantifying the literature of computer-aided instruction in medical education. Academic Medicine 75 (10), 1025-1028.

Agius, R., \& Bagnall, G. (1998). Development and evaluation of the use of the internet as an educational tool in occupational and environmental health and medicine. Occupational Medicine, 48 (5), 337-343.

Allen, M., Mabry, E., Mattrey, M., Bourhis, J., Titsworth, S., \& Burrell, N. (2004). Evaluating the effectiveness of distance learning: a comparison using meta-analysis. Journal of Communication, 54, 402-420.

Baumlin, K., Bessette, M., Lewis, C., \& Richardson, L. (2000). EMCyberSchool: An evaluation of computer-assisted instruction on the internet. Academic Emergency Medicine, 7 (8), 959-962.

Bedwell, W., \& Salas, E. (2010). Computer-based training: capitalizing on lessons learned. International Journal of Training and Development 14 (3), 239-249.

Bell, D., Fonarow, G., Hays, R., \& Mangione, C. (2000). Self-study from web-based and printed guidline materials: A randomized, controlled trial among resident physicians. Annals of Internal Medicine, 132 (12), 938-946.

Block, A., Felix, M., Udermann, B., Reineke, D., \& Murray, S. (2008). Achievement and satisfaction in an online versus a traditional health and wellness course. Journal of Online Learning and Teaching, 4 (1), 57-66.

Boyle, T., Bradley, C., Chalk, P., Jones, R., \& Pickard, P. (2003). Using blended learning to improve student success rates in learning to program. Journal of Educational Media 28 (2\&3), 165-178.

Burke, M., Sarpy, S. A., Smith-Crowe, K., Chan-Serafin, S., Salvador, R., \& Islam, G. (2006). Relative Effectiveness of Worker Safety and Health Training Methods. American Journal of Public Health, 96 (2), 315-324.

Chumley-Jones, H., Dobbie, A., \& Alford, C. (2002). Web-based learning: sound educational method or hype? A review of the evaluative literature. Academic Medicine, 77, 86-93.

Cohen, V. (2003). A model for assessing distance learning instruction. Journal of Computing in Higher Education, 14 (2), 98-120.

Curran, V., Hoekman, T., Gulliver, W., Landells, I., \& Hatcher, L. (2000). WWeb-based continuing medical education (II): Evaluation study of computer-mediated continuing medical education. The Journal of Continuing Education in the Health Profession, 20, 106-119.

DeBourgh, G. (1999). Technology is the tool, teaching is the task: Student satisfaction in distance learning. Society for Information Technology and Teacher Education International Conference, (pp. 1-8). San Antonio.

DeRouin, R., Fritzsche, B., \& Salas, E. (2004). Optimizing e-learning: reserach-based guidelines for learnercontrolled training. Human Resource Management Journal, 43 (2\&3), 147-162.

Engel, S., Crandall, J., Basch, C., Zybert, P., \& Wylie-Rosett, J. (1997). Computer-assisted diabetes nutrition education increases knowledge and self-efficacy of medical students. The Diabetes Educator, 23 (5), $545-549$.

Field, A. (2009). Discovering Statistics Using SPSS. London: Sage Publications.

Francis, B., Mauriello, S., Phillips, C., Englebardt, S., \& Grayden, S. (2000). Assessment of online continuing dental education in north carolina. The Journal of Continuing Education in the Health Profession, 20, 76-84. 
Harris, J., Salasche, S., \& Harris, R. (2001). Can internet-based continuing medical education improve physicians' skin cancer knowledge and skills? Journal of General Internal Medicine, 16, 50-56.

Horsch, A., Balbach, T., Melnitzki, S., \& Knauth, J. (2000). Learning tumor diagnostics and medical image processing via the WWW - The case-based radiological textbook ODITEB. International Journal of Medical Informatics, 58-59, 39-50.

Hsu, L.-L., \& Hsieh, S.-I. (2011). Effects of a blended learning module on self-reported learning performances in baccalaureate nursing students. Journal of Advanced Nursing, 2435-2444.

Kronz, J., Silberman, M., Allsbrook Jr., W., \& Epstein, J. (2000). A web-based tutorial improves practicing pathologists' gleason grading of images of prostate carcinoma specimens obtained by needle biopsy: Validation of a new medical education paradigm. The American Cancer Society, 89 (8), 1818-1823.

Lipman, A., Sade, R., Glotzbach, A., Lancaster, C., \& Marshall, M. (2001). The incremental value of internet-based instruction as an adjunct to classroom instruction: A prospective randomized study. Academy of Medicine, 76 (10), 72-76.

Melton, B., Graf, H., \& Chopak-Foss, J. (2009). Achievement and satisfaction in blended learning versus traditional general health course designs. International Journal for the Scholarship of Teaching and Learning, 3 (1), 1-13.

Osguthorpe, R., \& Graham, C. (2003). Blended learning environments: Definitions and directions. The Quarterly Review of Distance Education, 4 (3), 227-233.

Overbaugh, R. (1994). Reserach-based guidelines for computer-based instruction development. Journal of Reserach on Computing in Education 27 (1), 29-48.

Pereira, J., Pleguezuelos, E., Meri, A., Molina-Ros, A., Molina-Tomas, C., \& Masdeu, C. (2007). Effectiveness of using blended learning strategies for teaching and learning human anatomy. Medical Education, 41, 189-195.

Perryer, G., Walmsley, A., Barclay, C., Shaw, L., \& Smith, A. (2002). Development and evaluation of a stand-alone web-based CAL program. European Journal of Dental Education, 4 (3), 118-123.

Rivera, J., \& Rice, M. (2002). A comparison of student outcomes \& satisfaction between traditional \& web based course offerings. Online Journal of Distance Learning Administration, 5 (3).

Rose, M., Frisby, A., Hamlin, M., \& Jones, S. (2000). Evaluation of the effectiveness of a web-based graduate epidemiology course. Computers in Nursing, 18 (4), 162-167.

Sakowski, H., Rich, E., \& Turner, P. (2001). Web-based case simulations for a primary care clerkship. Academic Medicine, 76 (5), 547.

Smyth, S., Houghton, C., Cooney, A., \& Casey, D. (2012). Sutdents' experiences of blended learning across a range of postgraduate programmes. Nurse Education Today, 32, 464-468.

Woo, M., \& Kimmick, J. (2000). Comparison of internet versus lecture instructional methods for teaching nursing research. Journal of Professional Nursing, 16 (3), 132-139. 